\title{
Penentuan Viskositas Larutan Gula Menggunaan Metode Vessel Terhubung Viscosimeter Berbasis Video Based Laboratory dengan Software Tracker
}

\author{
Rr. Sinta Kusuma Ningrum, Moh. Toifur \\ Program Studi Magister Pendidikan Fisika, Universitas Ahmad Dahlan, \\ Jl. Pramuka Sidikan Yogyakarta, Indonesia \\ Surat-e: sinta_kningrum@yahoo.com
}

Telah dilakukan uji yang bertujuan untuk menentukan viskositas larutan gula. Metode yang digunakan adalah metode vessel terhubung viscosimeter. Hubungan antara $-\ln (2 \mathrm{hI} / \mathrm{hO}-\mathrm{I})$ terhadap $t$ dinyatakan dengan persamaan $-\ln (2 \mathrm{hI} / \mathrm{hO}-\mathrm{I})=(\pi \mathrm{D} 4 \mathrm{\rho g} / \mathrm{I} 28 \mathrm{AL} \eta) t$. Penelitian dimulai dengan menentukan viskositas air murni sebagai kalibrasi alat, dari hasil kalibrasi diperoleh nilai konversi sebesar 285, 49. Kemudian nilai ini selanjutnya digunakan dalam penentuan nilai viscositas larutan gula. Penentuan nilai koefisien viscositas larutan gula dilakukan dengan fitting data menurut garis lurus, $\mathrm{h}-\ln (2 \mathrm{hI} / \mathrm{hO}-\mathrm{I})$ sebagai sumbu vertikal dan $t$ sebagai sumbu horizontal, dengan $a$ adalah gradien garis. Dari hasil analisis diperoleh nilai viskositas larutan gula I0 \% adalah I,02 $\pm 0,02$ poise, $20 \%$ adalah $1,05 \pm 0,02$ poise, dan $30 \%$ adalah $1,13 \pm 0,02$ poise.

Kata kunci: viskositas, vessel terhubung viscosimeter, tracker.

\section{Pendahuluan}

Salah satu sifat dari zat cair adalah memiliki koefisien kekentalan yang berbeda-beda. Kekentalan atau viskositas pada zat cair terjadi karena adanya gaya kohesi sedangkan pada zat gas viskositas terjadi karena adanya tumbukan antara molekul. Viskositas menentukan kemudahan suatu molekul bergerak karena adanya gesekan antar lapisan material. Fluida yang lebih cair akan lebih mudah mengalir.

Kecepatan aliran berbeda karena adanya perbedaan viskositas. Besarnya viskositas dinyatakan dengan suatu bilangan yang menyatakan kekentalan suatu zat cair. Viskositas yang dimiliki setiap fluida berbeda dan dinyatakan secara kuantitatif oleh koefisien viskositas $\eta$ (Giancoli, 200I: 347).

Apabila zat cair tidak kental maka koefisien viscositasnya sama dengan nol sedangkan pada zat cair kental bagian yang menempel dinding mempunyai kecepatan yang sama dengan dinding. Salah satu alat yang digunakan untuk mengukur viskositas adalah viskosimeter.

Penelitian yang dilakukan oleh Ortega, dkk. (2007) menggunakan teknik viskosimeter bejana berhubungan. Bejana yang digunakan adalah tabung actylic transparan dihubungkan dengan tabung kapiler gelas. Penelitian bertujuan untuk membandingkan nilai viskositas air dengan variasi temperatur. Hasil pengukuran pada temperatur $(6,7$ $\pm 0, \mathrm{I}){ }^{\circ} \mathrm{C},(16,9 \pm 0, \mathrm{I})^{\circ} \mathrm{C},(22,5 \pm 0, \mathrm{I})^{\circ} \mathrm{C}$, dan $(28,3 \pm$ $0, \mathrm{I}){ }^{\circ} \mathrm{C}$, masing-masing nilai viskositasnya adalah $\mathrm{I}, 57$ mPa.s, I,I2 mPa.s, 0,92 mPa.s, dan 0,8I mPa.s.

Berdasarkan penelitian Mujiman (2008) dengan menggunakan sensor fototransistor dan penampil LCD untuk mengetahui nilai kekentalan oli Mesran sesuai standar SAE I0-SAE40. Hasil pengukuran yang paling mendekati nilai viskositasnya dengan nilai viskositas dari pertamina hanya satu sampel saja dari empat sampel yang digunakan. Penelitian ini dilakukan pada suhu ruang.

Berdasarkan penelitian yang dilakukan Budianto (2008), telah diuji kekentalan air, minyak goreng, oli, serta pengaruh suhu terhadap kekentalan masing-masing cairan. Metode yang digunakan adalah metode bola jatuh. Dari penelitian menunjukan bahwa kekentalan air, minyak goreng, dan oli pada suhu $27^{\circ} \mathrm{C}$ berturut-turut yaitu $(0,259 \pm 0,0 \mathrm{I})$ poise, $(2,296 \pm 0,0 \mathrm{I})$ poise, $(8,5 \mathrm{I} 9 \pm 0, \mathrm{I} 5 \mathrm{I})$ poise. Pada suhu 90 ${ }^{\circ} \mathrm{C}$ nilai kekentalan air, minyak goreng, dan oli masingmasing adalah $(0,234 \pm 0,013)$ poise, $(I, 353 \pm 0,048)$ poise, ( $1,492 \pm 0,043)$ poise.

Penelitian Widayanti dkk (20II) untuk menentukan koefisien viskositas larutan gula dengan metode pipa kapiler. Koefisien viskositas dihitung melalui analisis regresi linier hubungan tinggi larutan gula $h$ terhadap debit alir $Q$, dan pengambilan data untuk penentuan koefisien viskositas 
dilakukan dengan mengukur tinggi larutan gula $h$ dan debit alinya $Q$ yang dilakukan secara berulang sebanyak lima kali. Koefisien viskositas dihitung dari gradien garis hasil regresi $h$ terhadap $Q$. Dari lima tinggi larutan gula berbeda diperoleh nilai viskositas larutan gula $(0,384 \pm 0,073)$ poise.

Penulis melihat bahwa dari percobaan-percobaan terdahulu tersebut semua percobaan masih menggunakan sistem pengambilan data yang manual, sehingga hasil yang diperoleh kurang akurat. Selain itu alat ukur viskositas yang saat ini beredar di masyarakat harganya sangat mahal sehingga kebanyakan hanya digunakan untuk kebutuhan industri. Untuk itu penulis mengadakan penelitian penentuan visositas zat cair menggunaan metode vessel terhubung viscosimeter berbasis video based laboratory dengan software Tracker. Metode ini sangat sederhana namun memiliki tingkat ketelitian yang lebih tinggi.

\section{Kajian Pustaka}

Menurut Ghazali (2009) viskositas merupakan suatu tendensi untuk melawan aliran cairan karena resistensi suatu bahan yang mengalami perubahan bentuk bila bahan tersebut dikenai gaya. Viskositas biasanya berhubungan dengan konsistensi dan tendensi. Konsistensi dapat didefinisikan sebagai ketidakmauan suatu bahan untuk melawan perubahan bentuk bila suatu bahan mendapat gaya gesekan. Gesekan ini timbul sebagai hasil perubahan bentuk cairan yang disebabkan karena adanya resistensi yang berlawanan. Jika tenaga diberikan pada suatu cairan, tenaga ini akan menyebabkan suatu peubahan bentuk, yang disebut sebagai aliran.

Viskositas cairan yang bersifat Newtonian tidak berubah dengan adanya perubahan gaya gesekan antar permukaan cairan dengan dinding. Cairan newtonian biasanya merupakan cairan murni secara kimiawi dan homogen secara fisikawi. Contohnya adalah larutan gula, air, minyak, sirup, gelatin, dan susu (Ghazali, 2009).

Viskositas $(\eta)$ berhubungan dengan besarnya gaya gesekan antarlapis zat cair itu, dan juga antara zat cair dengan dinding pipanya. Fluida cair yang mengalir di dalam pipa, jenis alirannya dapat berupa aliran laminar atau aliran turbulen. Kedua jenis aliran itu terkait dengan nilai $\eta$, massa jenis $(\rho)$, dan kelajuan alir $(v)$ zat cair, serta diameter pipa $(D)$ dimana fluida itu mengalir. Hal itu dinyatakan dalam bilangan Reynold (Re) (Jati dkk, 20I0):

$$
R_{e}=\frac{\rho v D}{\eta}
$$

ketika Re kecil (< 2000) maka zat cair mengalir secara laminer (setiap bagian zat cair itu mengalir menuruti garis arusnya sendiri, dan garis arus itu tidak pernah saling berpotongan). Sebaliknya, bila $\operatorname{Re}$ besar (> 4000) maka fluida mengalir secara turbulen (terjadi arus pusar). Persamaan (I) memperlihatkan bahwa $\operatorname{Re}$ kecil bila $\eta$ besar. Artinya, keberadaan $\eta$ yang semakin besar membuat aliran cenderung laminer. Ketika aliran zat cair itu laminer, maka kejadian tersebut memenuhi persamaan Poiseuille.

Aliran laminer cairan newtonian yang melewati pipa mengikuti hukum poiseuille. Untuk pipa dengan luas penampang $A$, jari- jari $r$, dan kecepatan aliran fluida $v$ maka debit fluida

$$
\mathrm{Q}=\mathrm{Av} \text {. }
$$

Debit fluida adalah besaran yang menyatakan volume fluida yang mengalir melalui suatu penampang tertentu dalam satuan waktu tertentu maka debit fluida (Kanginan, 2004 : 208) dapat menjadi

$$
\mathrm{Q}=\frac{\mathrm{V}}{\mathrm{t}} \text {. }
$$

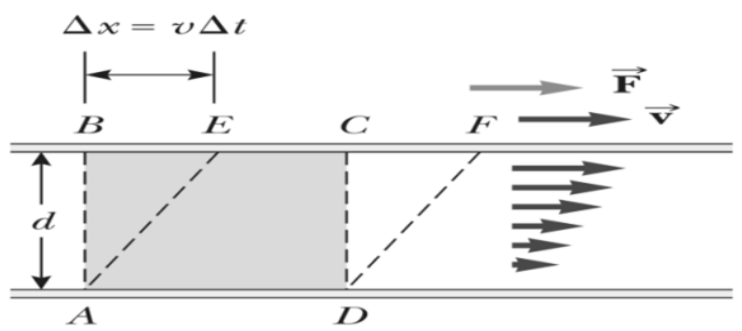

Gambar I. Lapisan cairan antara dua permukaan padat di mana permukaan bawah adalah diam dan permukaan atas bergerak ke kanan dengan kecepatan $v$ (Serway dan Jewett, 2004: 302)

Gerakan fluida antara dua plat paralel seperti pada gambar I. Permukaan bagian bawah adalah tetap diam, dan permukaan atas bergerak ke kanan dengan kecepatan $\vec{v}$ di bawah gerakan gaya eksternal $\vec{F}$. Karena gerakan ini, sebagian dari cairan terdistorsi dari bentuk aslinya, $\mathrm{ABCD}$, pada satu instan untuk membentuk AEFD beberapa saat kemudian. Gaya yang dibutuhkan untuk memindahkan pelat atas dan mendistorsi cairan sebanding dengan kedua daerah tersebut A dalam kontak dengan cairan dan $\mathrm{v}$ kecepatan fluida. Selanjutnya, gaya adalah berbanding terbalik dengan jarak $\mathrm{d}$ antara dua lempeng. Kita dapat mengekspresikan perbandingan ini sebagai $\mathrm{F} \propto \mathrm{Av} / \mathrm{d}$. Gaya yang dibutuhkan untuk memindahkan pelat atas pada kecepatan tetap $v$. Oleh karena itu

$$
\mathrm{F}=\eta \mathrm{A} \frac{\mathrm{v}}{\mathrm{d}}
$$

dengan $\eta$ adalah koefisien viskositas (Serway dan Jewett, 2004: 302-303). 


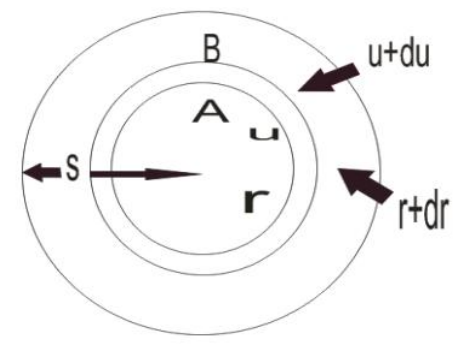

Gambar 2. Diameter pipa Kapiler penampang lintang dengan jari-jari $(0,148 \pm 0,001) \mathrm{cm}$. (Tyler, 1967: 63)

Kecepatan aliran air pada suatu pipa kecil bervariasi dari 0 ditepi ke nilai maksimum sepanjang poros. Misalkan dua permukaan $\mathrm{A}$ dan $\mathrm{B}$ terdiri dari lapisan tabung tipis antara jari-jari $r$ dan $r+\mathrm{d} r$ dan kecepatan aliran di $\mathrm{A}$ dan $\mathrm{B}$ masing-masing menjadi $u$ dan $u+\mathrm{d} u$.

Kemudian dari definisi koefisien viskositas $(\eta)$, tahanan kekentalan antara dua permukaan diberikan oleh luas permukaan dikali $\eta$ dan dikalikan dengan gradien kecepatan. Jadi, tahanan kekentalan $(F)$ di A pada sebuah tabung 1 panjang adalah

$$
\mathrm{F}=2 \pi r \ln \frac{\mathrm{du}}{\mathrm{dr}}
$$

dan tahanan kekentalan $(F+d F)$ di B adalah

$$
F+d F=2 \pi r l \eta \frac{d u}{d r}+\frac{d}{d r}\left(2 \pi r l \eta \frac{d u}{d r}\right) d r .
$$

Oleh karena itu tahanan kekentalan pada tabung tabung cenderung menjaga pergerakan cairan saat diam

$$
d F=\frac{d}{d r}\left(2 \pi r l \eta \frac{d u}{d r}\right) d r,
$$

dan ketika gerakan stabil diperoleh, gaya ditentang oleh dorongan hidrostatik akibat perbedaan tekanan $P$ pada ujung tabung, sehingga

$$
2 \pi r d r P=-d F=\frac{d}{d r}\left(2 \pi r l \eta \frac{d u}{d r}\right) d r,
$$

atau

$$
-\frac{d}{d r}\left(2 \pi r l \eta \frac{d u}{d r}\right)=2 \pi r P,
$$

mengintegrasikan

$$
-2 \pi r \ln \frac{d u}{d r}=2 \pi \frac{r^{2}}{2} P+A
$$

Tetapi $A=0$ sejak du/dr=0 ketika $r=0$, yaitu

$$
-2 \ln \frac{\mathrm{du}}{\mathrm{dr}}=\mathrm{rP}
$$

ketika persamaan (II) diintegralkan, maka

$$
-2 \ln \mathrm{u}=\frac{\mathrm{r}^{2} \mathrm{P}}{2}+\mathrm{B}
$$

tetapi $B=-\mathrm{Ps} 2 / 2$ sejak $u=0$ ketika $r=s$. maka

$$
\mathrm{u}=\frac{\mathrm{P}}{4 \ln }\left(\mathrm{s}^{2}-\mathrm{r}^{2}\right)
$$

sejak kuantitas aliran per detik mengalir ke tabung kecil maka diperoleh

$$
\mathrm{u} 2 \pi \mathrm{rdr}=\frac{\mathrm{P}}{2 \ln }\left(\mathrm{s}^{2}-\mathrm{r}^{2}\right) \mathrm{dr} .
$$

Jadi untuk kuantitas total $Q$ pada tabung yang mengalir per detik adalah (Tyler, 63)

$$
\mathrm{Q}=\frac{\mathrm{P} \pi}{2 \ln } \int_{0}^{\mathrm{s}}\left(\mathrm{s}^{2} \mathrm{r}-\mathrm{r}^{3}\right) \mathrm{dr}=\frac{\mathrm{P} \pi}{2 \ln }\left[\frac{\mathrm{s}^{2} \mathrm{r}^{2}}{2}-\frac{\mathrm{r}^{4}}{4}\right]_{0}^{\mathrm{s}},
$$

dengan memisalkan $2 t=D$ pada perbedaan tekanan sebesar $\Delta p$, dapat disimpulkan aliran fluida pada volume konstan dapat ditunjukan melalui persamaan

$$
\mathrm{Q}=\frac{\pi \Delta \mathrm{p}}{128 \mathrm{L \eta}} \mathrm{D}^{4}
$$

Persamaan I6 dikenal sebagai hokum poiseulle, dengan $Q$ debit aliran air. Sejak pergerakan air pada pipa vessel sangat lambat, dan tekanan $P \mathrm{I}$ dan $P 2$ pada ujung pipa kapiler dapat dekati dengan tekanan hidrostatik,

$$
P_{1}=P_{0}+\rho g h_{1}
$$

dan

$$
\mathrm{P}_{2}=\mathrm{P}_{0}+\rho g \mathrm{~h}_{2}
$$

dengan $P O$ adalah tekanan atmosfir, $\rho$ massa jenis dari zat cair yang digunakan, dan $\mathrm{g}$ perceptan gravitasi, dengan nilai $g=(9,78 \pm 0,07) \mathrm{m} / \mathrm{s}^{2}$ yang sesuai dengan percepatan gravitasi bumi daerah Yogyakarta (Chuzam dan Oktova, 2010: 3I4), dengan substitusi pers. (I6) ke pers. (I7) maka

$$
\Delta \mathrm{P}=\mathrm{P}_{2}-\mathrm{P}_{1}=\rho g\left(\mathrm{~h}_{2}-\mathrm{h}_{1}\right),
$$




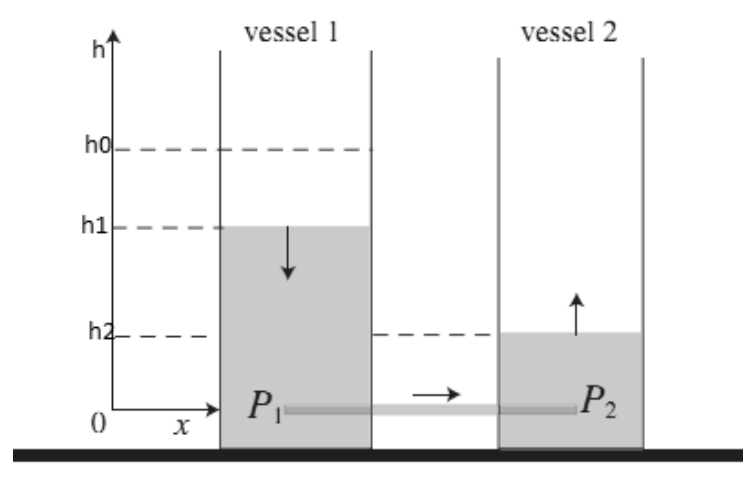

Gambar 3. Dua tabung silinder yang dihubungkan oleh pipa kapiler (Ortega, dkk., 200I)

dengan mengasumsikan tekanan selalu konstan dan volume cairan yang ada dalam pipa vessel konstan.sehingga debit aliran air pada pipa kailer dapat ditunjukan dengan persamaan

$$
Q=\frac{\pi D^{4} \rho g}{128 L \eta}\left(h_{0}-2 h_{1}\right)
$$

dan nilai $Q$ juga dapat diperoleh dari

$$
Q=A \frac{d h}{d t}
$$

dengan $A$ merupakan luas daerah pada pipa vessel, dengan mensubstitusika pers (20) ke (2I) maka diperoleh

$$
A \frac{d h}{d t}=\frac{\pi D^{4} \rho g}{128 L \eta}\left(z_{0}-2 z_{1}\right)
$$

dan

$$
\frac{d h}{d t}=\frac{\pi D^{4} \rho g}{128 A L \eta}\left(h_{0}-2 h_{1}\right)
$$

maka

$$
\frac{d h_{1}}{\left(h_{0}-2 h_{1}\right)}=\frac{\pi D^{4} \rho g}{128 A L \eta} d t
$$

sehingga

$$
-\ln \left(\frac{2 h_{1}}{h_{0}}-1\right)=\frac{\pi D^{4} \rho g}{128 A L \eta} d t
$$

Jika $\Delta t$ divariasi dengan $\pi, D, \rho, g, A, L$ dan $\boldsymbol{\eta}$ tetap, maka persamaan (25) merupakan persamaan linier berbentuk

$$
\hat{y}_{i}=a x_{i}+b
$$

dengan variabel $y=v, x=\Delta h$. Untuk mengetahui garis lurus terbaik hubungan kecepatan alir dan perubahan ketinggian diperoleh dengan menggunakan persamaan (26)
Penentuan Viskositas Larutan Gula Menggunaan Metode Vessel Terhubung Viscosimeter Berbasis Video Based Laboratory dengan Software Tracker

dapat diperoleh nilai $a$ dan $b$ (Bevington dan Robinson: 2003) dengan

$$
a=\frac{1}{\Delta}\left(N \Sigma x_{i} y_{i}-\Sigma x_{i} \Sigma y_{i}\right),
$$

dan

$$
b=\frac{1}{\Delta}\left(\Sigma x_{i}^{2} \Sigma y_{i}-\Sigma x_{i} \Sigma x_{i} y_{i}\right),
$$

dengan

$$
\Delta=N \Sigma x_{i}^{2}-\left(\Sigma x_{i}\right)^{2}
$$

dan ralat baku estimasi regresi adalah

$$
\sigma^{2}=\frac{1}{N-2} \Sigma\left(y_{i}-\hat{y}_{i}\right)^{2},
$$

Ralat adapat dihitung dari

$$
\sigma_{a}=\sqrt{\frac{N \sigma^{2}}{\Delta}}
$$

dan ralat $b$ dapat dihitung dari

$$
\sigma_{b}=\sqrt{\frac{\sigma^{2}}{\Delta} \Sigma x_{i}^{2}}
$$

berdasarkan hasil regresi, diperoleh

$$
a=\frac{\pi D^{4} \rho g}{128 \mathrm{AL \eta}}
$$

dengan $A=\pi D(D+L)$ maka

$$
a=\frac{D^{3} \rho g}{128(D+L) L \eta}
$$

Faktor konfersi hasil pengukuran adalah

$$
K=\frac{\eta_{\text {acuan }}}{\eta_{\text {ekperimen }}}
$$

maka nilai viskositas dapat diperoleh dari

$$
\eta=\frac{K D^{3} \rho g}{128(D+L) L a}
$$

dan nilai ralatnya dapat diperoleh dari

$$
\begin{gathered}
S_{\eta}=\left\{\left(\frac{\delta \eta}{\delta D} S_{d}\right)^{2}+\left(\frac{\delta \eta}{\delta g} S_{g}\right)^{2}+\right. \\
\left.\left(\frac{\delta \eta}{\delta L} S_{L}\right)^{2}+\left(\frac{\delta \eta}{\delta a} S_{a}\right)^{2}\right\}^{1 / 2}
\end{gathered}
$$




\section{Metode Penelitian}

Percobaan penentuan koefisien viskositas $(\eta)$ dengan pipa kapiler sepanjang $(10,00 \pm 0,0 \mathrm{I}) \mathrm{cm}$ dan diameter dalam $(0,20 \pm 0,05) \mathrm{cm}$. Alat dan bahan yang digunakan dalam eksperimen ini adalah vessel viscosimeter, software tracker, jangka sorong, thermometer alkohol, penggaris, dan air. Langkah-langkah percobaannya sebagai berikut

a. Diameter dan panjang pipa kapiler diukur menggunakan jangka sorong.

b. Suhu air diukur menggunakan termometer.

c. Tabung 2 diisi dengan air dengan volume $30 \mathrm{~mL}$.

d. kemudian di rekam menggunakan kamera digital sampai air pada kedua tabung memiliki ketinggian yang sama.

e. Kemudian file ditransfer ke komputer dengan menggunakan ekstensi .mov.

f. Setelah itu file dibuka menggunakan software trakker, penurunan volume air ditrak sampai volueme air pada kedua tabung sama tingginya.

g. Setelah selesai pengambilan data lalu daiambil data perubahan ketinggian dan waktu kemudaian dianalisis menggunakan bantuan Ms. Office Excel untuk mendapatkan fungsi regresi linier.

h. Kemudian diulang untuk berbagai larutan gula, I0\%, $20 \%$ dan $30 \%$.

i.

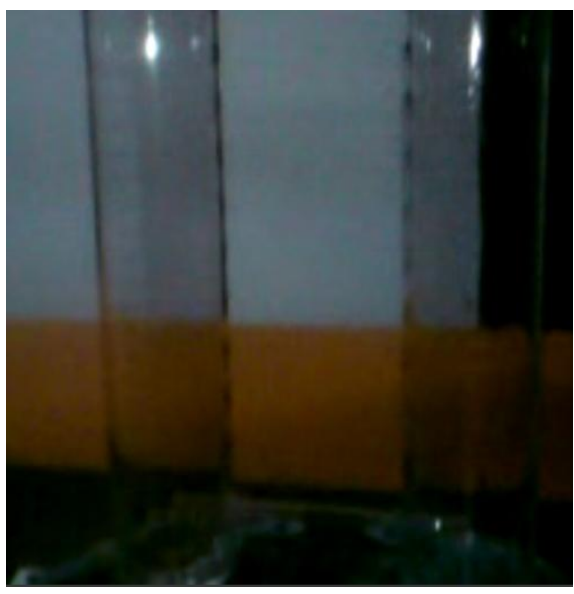

Gambar 4. Viscosimeter vessel terhubung

\section{Hasil Penelitian dan Pembahasan}

Penentuan nilai viskositas larutan gula dimulai dengan melakukan kalibrasi terhadap viskosimeter vessel terhubung menggunakan air murni. Diperoleh hasil nilai gradient garis $(0,16 \pm 0,09)$ yang ditunjukan gambar 3. Sehingga diperoleh
Penentuan Viskositas Larutan Gula Menggunaan Metode Vessel Terhubung Viscosimeter Berbasis Video Based Laboratory dengan Software Tracker

nilai konversi sebesar 285,4849, dan nilai ini yang selanjutnya digunakan dalam penentuan nilai viscositas larutan gula.

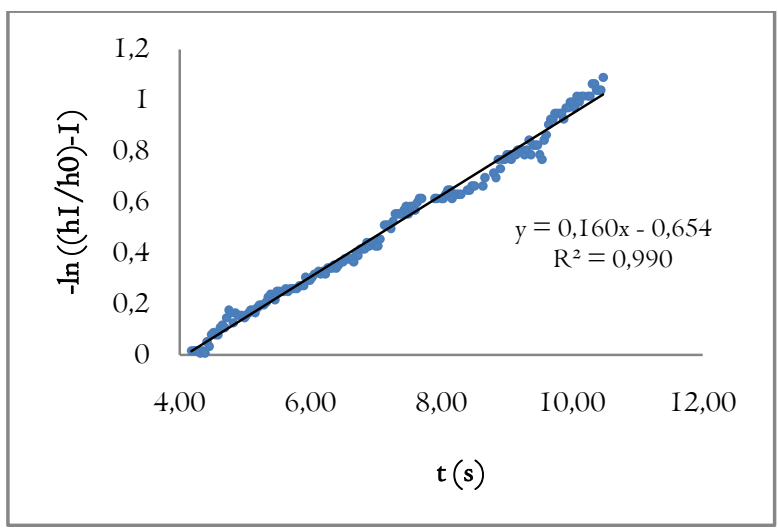

Gambar 5. Grafik hasil analisis data air murni

Dari hasil pengambilan data pada larutan gula I0\%, 20\% dan 30\% diperoleh hasil seperti yangditunjukan pada gambar 6,

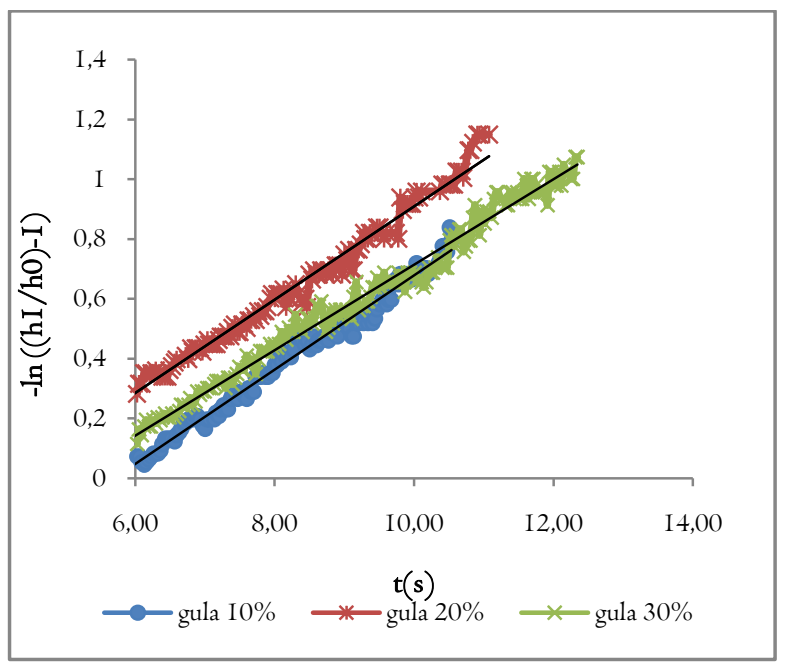

Gambar 5. Grafik hasil analisis data air murni

Dari hasil analissi data diperoleh nilai koefisien viscositas larutan gula ditunjukan pada tabel I.

Tabel I. Hasil perhitungan viskositas larutan gula

\begin{tabular}{cccc}
\hline No. & Kadar (\%) & Gradien & Viskositas (poise) \\
\hline 1 & 10 & $157,000 \pm 0,003$ & $1,02 \pm 0,02$ \\
2 & 20 & $155,000 \pm 0,001$ & $1,05 \pm 0,02$ \\
3 & 30 & $142,000 \pm 0,001$ & $1,13 \pm 0,02$ \\
\hline
\end{tabular}

Percobaan penentuan koefisien viskositas larutan gula menggunakan metode vessel terhubung dengan bantuan 
software tracker terbukti lebih teliti. Namun dalam penelitian ini perlu diperbaiki agar nilai koreksi tidak terlalu besar, hal ini dimungkinkan ketika pengambilan data video yang digunakan masih kurang jelas sehingga tracking data tidak maksimal. Saran untuk penelitian selanjutnya agar menggunakan kamera dengan resolusi tinggi agar video yang dihasilkan lebih jelas sehingga data lebih akurat.

\section{Kesimpulan}

Dari hasil analisis dengan menggunakan metode vessel terhubung viscosimeter berbasis video based laboratory diperoleh nilai viscositas lautan gula I0 \% adalah (I,02 $\pm 0,02)$ poise, $20 \%$ adalah $(1,05 \pm 0,02)$ poise, dan $30 \%$ adalah $1,13 \pm 0,02$ poise.

\section{Kepustakaan}

Bevington, P.R dan Robinson, D.K. 2003. Data Reduction and Error Analysis for the Physical Sciences. Newyork: McGraw-Hill.98-I I4).

Budianto, A. 2008. Metode Penentuan Koefisien Kekentalan Zat Cair Dengan Menggunakan Regresi Linear Hukum Stokes. p.I57-166. Diakses dari http://jurnal.sttnbatan.ac.id/wpcontent/uploads/200 8/I2/I2- anwarI57-I66.pdf

Chuzam, A. Dan Oktova, R. 2010. Penentuan Tara Kalor Mekanis Secara Teliti Dengan Metode Gesekan Dua Kerucut. Diakses tanggal I6 April 201 I pukul II.45 dari http//:www.fi.itb. ac.id/ $\sim$ dede/Seminar\%20HFI\%2010/Cd\%20Procee dings/indek.html. p.3I4.

Diliyanti, A. Henny, G. dan Indah, H. 2009. Viskositas. Diakses tanggal 26 maret 20II, pukul 20.28 dari http://morehigher. blogspot.com/2009/09/fisikafarmasi.html.

Ghazali, R.A. 2009 . Kekentalan. Diakses tanggal 26 maret 20II, pukul 20.28 dari http://kurkum I3.blogspot.com/2009/I I/kekentalan.html.

Giancoli, Douglas C. 200I. Fisika Jilid I. Jakarta: Erlangga.

Jati, B.M.E, Karyono, dan Supriyatin. 2010. Penyetaraan Nilai Viscositas Terhadap Indeks Bias pada Zat Cair Bening. Berkala Fisika Vol.13, No 4, Oktober 2010, hal II9-I24.ISSN I4I0-9662.

Kanginan, M. 2004. Fisika Untuk SMA Kelas XI. Jakarta: Erlangga. p.208
Ortega, F. M., Pavioni, O.D., dan Dominguez, H.L. 2007. A Communicating-Vessel Viscosimeter, American journal of Physics pdf., vol.45, p. I I6-I I8. Diakses dari http://aapt.org/ajp.

Serway, R.A. dan Jewett, J.W. 2004. Physics For Scientisc and Engineers pdf. California : Thomson Brooks/Cole. P.302-303.

Tyler, F. I967. A Laboratory Manual of Physics. London : Erdward Arnold. p.62-63

Widayanti, L., Siti Habibah, Wiwik Erliyana, Okimustava. 20II. Penentuan Koefisien Viskositas Larutan Gulamenggunakan Metode Pipa Kapiler Hukum Poiseuille. Prosiding seminar nasional endidikan fisika dan fisika 20II, Universitas Ahmad Dahlan Yogyakarta 